\title{
Transesophageal Doppler Echocardiographic Pattern of Pulmonary Venous Flow in Severe Mitral Stenosis
}

\author{
Fawzia Y. Al Kandaria Abdul-Latif Salama ${ }^{a}$ George Cherian ${ }^{b}$ \\ aDepartment of Cardiology, Chest Diseases Hospital, Ministry of Public Health, and \\ bDepartment of Medicine, Kuwait University, Safat, Kuwait
}

\section{Key Words}

Transesophageal echocardiography • Systolic peak flow velocity - Diastolic peak flow velocity - Atrial reversal peak flow velocity · Systolic velocity-time integral . Diastolic velocity-time integral · Fractional shortening - Left ventricular ejection fraction

\begin{abstract}
Objectives: Analysis of the pulmonary venous flow enables an evaluation of cardiac hemodynamics. This study was conducted to evaluate the effect of severe mitral stenosis on the pulmonary venous flow both in sinus rhythm and atrial fibrillation. Methods: We studied 38 patients with isolated severe mitral stenosis (mitral valve area index $\leq 0.75 \mathrm{~cm}^{2}$ ) by pulsed wave Doppler transesophageal echocardiography of the left upper pulmonary vein. Twenty-six patients $(68 \%)$ were in sinus rhythm and $12(32 \%)$ in
\end{abstract}

\begin{tabular}{ll}
\hline KARGER & (1) 1999 S. Karger AG, Basel \\
Fax +41 61 306 1234 34 & \\
$\begin{array}{l}\text { E-Mail karger@karger.ch } \\
\text { www.karger.com }\end{array}$ & $\begin{array}{l}\text { Accessible online at: } \\
\text { http://BioMedNet.com/karger }\end{array}$
\end{tabular}

atrial fibrillation. Results: The peak systolic flow velocity was significantly lower in atrial fibrillation patients with blunted systolic flow pattern in $67 \%$, while the normal flow pattern with higher systolic-to-diastolic flow ratio was found in $69 \%$ of sinus rhythm patients. Pulmonary venous flow was significantly delayed in its onset and termination with atrial fibrillation compared to sinus rhythm even after correction for heart rate $(p<0.02, p<$ 0.04 , respectively). The pulmonary venous peak systolic flow velocity showed a significant negative correlation with the mean pulmonary pressure $(r=-0.424, p=0.011)$. Finally, there was a correlation between the pulmonary venous diastolic pressure half-time and the peak mitral gradient $(r=-0.327, p=$ $0.045)$, mean mitral gradient $(r=-0.369, p=$ $0.022)$ and Doppler mitral valve area $(r=$ $-0.422, p=0.008)$. Conclusion: Severe mitral stenosis is associated with a decreased pulmonary venous systolic flow and prolonged 
decay of the diastolic flow, and these changes are more marked in atrial fibrillation. These results can help to understand the hemodynamics of mitral stenosis and its interaction with the pulmonary circulation.

\section{Introduction}

Pulmonary venous flow is pulsatile in nature and normally consists of systolic and diastolic forward waves and a small atrial reversal flow. The systolic forward flow results from an atrial relaxation and the descent of the base of the heart during ventricular contraction, while the diastolic flow results from rapid ventricular filling from the left atrium and decay of the pressure gradient between the left atrium and left ventricle [1].

Mitral stenosis causes an alteration in the normal pulmonary venous flow pattern resulting in lower systolic-to-diastolic peak flow velocities and delay in the diastolic wave deceleration with progressively increasing severity of valve stenosis. Earlier reports have analyzed the pulmonary venous flow pattern in mitral stenosis with widely varying valve areas $[2,3]$. In this study, we investigated the influence of severe mitral valve stenosis on the pulmonary venous flow pattern as assessed by transesophageal Doppler echocardiography in patients both in sinus rhythm and atrial fibrillation.

\section{Methods}

\section{Study Patients}

The study was performed from January 1995 to January 1997 on 38 patients with symptomatic severe mitral stenosis undergoing transesophageal echocardiography (TEE) before cardiac catheterization to evaluate their suitability for balloon mitral valvotomy. There were 21 men and 17 women and the mean age was $39 \pm 10$ years. Twenty-six patients were in sinus

Transesophageal Doppler Echocardiographic Pattern of Pulmonary Venous Flow in Severe Mitral Stenosis rhythm and 12 in atrial fibrillation. All patients had normal left ventricular function and no more than mild (1+) mitral regurgitation or other valve lesions.

\section{Procedures}

All patients had full transthoracic echocardiographic examination using $3.37-\mathrm{MHz}$ imaging transducer and 2.5-MHz Doppler transducer connected to a Toshiba Ultrasound Imaging System (model SSH160A). They also underwent a complete TEE examination utilizing standard methods [4] using a $5-\mathrm{MHz}$ biplane transducer. An ECG lead was continuously monitored during the procedure. Left upper pulmonary vein tracing was used in all patients from the transverse short axis view and the pulmonary venous flow was recorded by TEE, by positioning the Doppler sample volume 1-2 cm distal to the orifice of the left upper pulmonary vein into the left atrium under color Doppler guidance. The Doppler beam was oriented as parallel as possible to the pulmonary venous flow without using angle correction. The study was recorded on a 1/2-inch video cassette for an off-line analysis. Furthermore, the pulmonary venous flow recordings were obtained at a paper speed of $50 \mathrm{~mm} / \mathrm{s}$.

\section{Echocardiographic Measurements}

M-mode measurements of the left ventricular dimensions, left ventricular ejection fraction, fractional shortening and left atrial size were determined using standard methods. Continuous wave Doppler transthoracic echocardiography across the mitral valve was performed to measure peak and mean pressure gradients, pressure half-time and mitral valve area. Mitral valve area index (MVAI; mitral valve area/BSA) was calculated and mitral valve area $<1 \mathrm{~cm}^{2}$ or MVAI $<0.75$ were considered as significant valve stenosis.

\section{TEE Measurements}

The presence or absence of left atrial thrombus and spontaneous echo contrast were noted. The degree of mitral regurgitation was assessed by Doppler color flow mapping [5] and the patients with more than mild mitral regurgitation were excluded. Furthermore, cardiac catheterization following TEE was performed in 31 out of 38 in the study group, confirming the absence or presence of only a mild degree of mitral regurgitation. We also measured the dimension of the orifice of the left upper pulmonary vein at the left atrium, at the end of diastole.

\section{Pulmonary Venous Flow Measurements}

All pulmonary venous flow measurements were averaged from three cardiac cycles in patients in sinus 


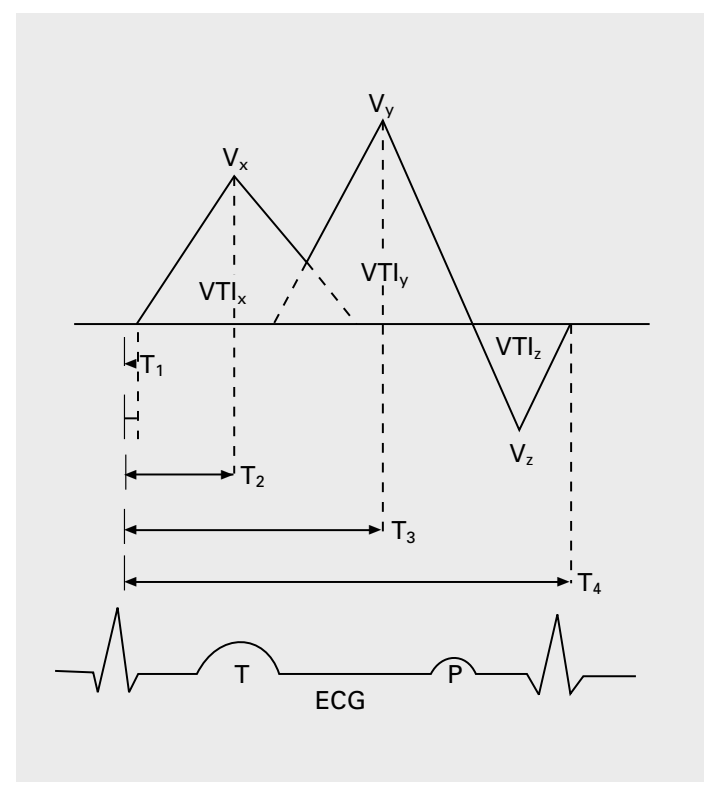

Fig. 1. Diagram of Doppler echocardiographic tracing of pulmonary venous flow velocity in sinus rhythm. Variables measured included: peak flow velocity of the second systolic forward $\left(\mathrm{v}_{\mathrm{x}}\right)$, diastolic forward $\left(\mathrm{v}_{\mathrm{y}}\right)$, and reversed diastolic $\left(\mathrm{v}_{\mathrm{z}}\right)$ waves; velocity-time integral of systolic forward flow $\left(\mathrm{VTI}_{\mathrm{x}}\right)$, diastolic forward flow $\left(\mathrm{VTI}_{\mathrm{y}}\right)$, and diastolic reversed flow $\left(\mathrm{VTI}_{\mathrm{z}}\right)$; time interval from peak of $\mathrm{R}$ wave on the ECG to the onset of systolic forward flow $\left(T_{1}\right)$, to $\mathrm{v}_{\mathrm{x}}\left(\mathrm{T}_{2}\right)$, to $\mathrm{v}_{\mathrm{y}}\left(\mathrm{T}_{3}\right)$, and to the end of pulmonary venous flow $\left(\mathrm{T}_{4}\right)$.

rhythm while five cardiac cycles were averaged in patients in atrial fibrillation. All measurements were calculated during off-line analysis using the software incorporated on the same echo machine (fig. 1).

The peak flow velocities of the second forward systolic $\left(\mathrm{v}_{\mathrm{x}}\right)$ and diastolic forward $\left(\mathrm{v}_{\mathrm{y}}\right)$ waves were measured in all patients, and peak flow velocity of reversed flow $\left(\mathrm{v}_{\mathrm{z}}\right)$ occurring during atrial contraction was obtained in patients in sinus rhythm. Forward systolic pumonary venous flow consists of two waves. The second wave was used because the first was not recorded in every patient, particularly in those with atrial fibrillation where an early systolic reversed wave coinciding with mitral closure was generally recorded [3]. Pulmonary venous systolic flow was considered as normal if the systolic/diastolic flow ratio was $\geq 1$ while a blunted pattern was defined as systolic/diastolic flow ratio $<1$
[5]. Velocity-time integrals in the three phases of the pulmonary venous flow were measured as follows. The systolic velocity-time integral (VTIx) was measured from the onset of the forward flow after the $\mathrm{R}$ wave peak on the ECG to the crossover of that wave with the zero line. The early diastolic velocity-time integral (VTIy) was measured from the onset of the diastolic forward wave to its crossover with the zero line. The velocity-time integral of atrial flow reversal (VTIz) was obtained from the onset to termination of the negative wave in late diastole. We also measured the time of onset of pulmonary venous flow from the $\mathrm{R}$ wave peak on $\mathrm{ECG}$, time from peak of $\mathrm{R}$ to $\mathrm{V}_{\mathrm{x}}$, time from peak of $\mathrm{R}$ to $\mathrm{v}_{\mathrm{y}}$ and to the end of the pulmonary venous flow. Furthermore, all these timings were corrected for heart rate by dividing the average of each time with the average R-R interval. Finally, the pulmonary venous diastolic wave deceleration time from the peak to the baseline was measured and the pulmonary venous diastolic pressure half-time was calculated by multiplying the deceleration time by a constant 0.29 [6].

\section{Cardiac Catheterization}

Thirty-one out of 38 patients had cardiac catheterization done 1 day after the TEE study. Cardiac output, pulmonary artery pressure, peak and mean mitral gradients were measured. Mitral valve area was calculated using the Gorlin formula [7]. The presence of mitral regurgitation and its severity when present were assessed on the left ventricular angiography.

\section{Statistical Analysis}

All data are expressed as mean \pm SD. Data for both groups of atrial fibrillation and sinus rhythm were compared by an independent sample t test. Pearson's correlation coefficients are calculated to relate pulmonary venous flow and other echocardiographic parameters. A two-tailed value $<0.05$ was considered statistically significant.

\section{Results}

\section{Echocardiographic and Doppler Mitral Finding (table 1)}

All patients had severe mitral stenosis with mean MVAI of 0.55 (31 out of 38 patients had cardiac catheterization following TEE with equivalent mean MVAI of 0.54 ).

All patients had normal left ventricular dimensions, left ventricular ejection fraction 
Table 1. Clinical, echocardiographic and Doppler mitral findings of 38 patients with mitral stenosis expressed as mean $\pm \mathrm{SD}$

\begin{tabular}{|c|c|c|c|}
\hline & \multicolumn{3}{|c|}{ Study group $(\mathrm{n}=38)$} \\
\hline & total & $\mathrm{SR}(\mathrm{n}=26)$ & $\mathrm{AF}(\mathrm{n}=12)$ \\
\hline Men/women & $21 / 17$ & $15 / 11$ & $6 / 6$ \\
\hline Age, years & $39 \pm 10$ & $35 \pm 8^{\mathrm{a}}$ & $\pm 10^{\mathrm{a}}$ \\
\hline NYHA (III-IV) & 35 & 23 & 10 \\
\hline Heart rate, beats/min & \pm 15 & \pm 15 & \pm 16 \\
\hline $\mathrm{LV}$ diastolic dimension, $\mathrm{mm}$ & $49 \pm 7$ & \pm 6 & \pm 8 \\
\hline LV systolic dimension, mm & \pm 6 & \pm 6 & \pm 6 \\
\hline LVEF, $\%$ & $63 \pm 8$ & $63 \pm 9$ & \pm 7 \\
\hline FS & $0.32 \pm 0.06$ & $0.32 \pm 0.07$ & $0.32 \pm 0.05$ \\
\hline Left atrium dimension, mm & $52 \pm 8$ & $50 \pm 7^{b}$ & $56 \pm 8^{b}$ \\
\hline Peak mitral gradient, mm Hg & \pm 6 & \pm 6 & \pm 4 \\
\hline Mean mitral gradient, $\mathrm{mm} \mathrm{Hg}$ & \pm 5 & $\pm 5^{c}$ & $\pm 4^{c}$ \\
\hline Mitral pressure half-time, ms & \pm 64 & $226 \pm 65^{d}$ & $\pm 52^{\mathrm{d}}$ \\
\hline MVAI(echo) & $0.55 \pm 0.13$ & $0.59 \pm 0.13^{\mathrm{e}}$ & $0.47 \pm 0.09^{\mathrm{e}}$ \\
\hline MVAI (cath.) & $0.54 \pm 0.12$ & $0.54 \pm 0.12$ & $0.54 \pm 0.12$ \\
\hline $\begin{array}{l}\text { Mean pulmonary artery pressure, } \\
\text { mm Hg }\end{array}$ & \pm 13 & \pm 14 & \pm 9 \\
\hline $\begin{array}{l}\text { SR }=\text { Sinus rhythm; } A F=\text { atria } \\
{ }^{\mathrm{a}} \mathrm{p}<0.001,{ }^{\mathrm{b}} \mathrm{p}<0.04,{ }^{\mathrm{c}} \mathrm{p}<0.0\end{array}$ & $\begin{array}{l}\text { ation. } \\
<0.04,{ }^{\mathrm{e}} \mathrm{p}<0.0\end{array}$ & & \\
\hline
\end{tabular}

and fractional shortening. Twenty-six patients $(68 \%)$ were in sinus rhythm whereas 12 $(32 \%)$ were in atrial fibrillation. There was an equal number of males and females in the atrial fibrillation group who were older than those in sinus rhythm $(\mathrm{p}<0.001)$.

Left atrial dimension was also significantly larger in the atrial fibrillation group $(\mathrm{p}<0.04)$. On the other hand, the mean left upper pulmonary vein dimension was the same in both groups (table 2). The mean mitral gradient was lower in atrial fibrillation. None of the patients had more than mild mitral regurgitation and only 2 patients had left atrial thrombus. Both were in atrial fibrillation without obstruction to pulmonary venous flow.

\section{Pulmonary Venous Flow Findings}

Out of 38 patients with severe mitral stenosis, $16(42 \%)$ had blunted systolic flow pattern and $22(58 \%)$ had a normal pulmonary venous flow pattern with higher systolic-to-diastolic flow (table 3 ). Blunted pattern predominates in the atrial fibrillation group (8 of 12 patients, $67 \%$; fig. 2), while both blunted and normal pattern were present in sinus rhythm patients ( 8 out of 26 patients and 16 out of 26 patients, respectively; fig. 3, 4).

The peak systolic flow velocity $\left(\mathrm{v}_{\mathrm{x}}\right)$ and the ratio of peak systolic-to-diastolic flow velocity $\left(\mathrm{v}_{\mathrm{x}} / \mathrm{v}_{\mathrm{y}}\right)$ were significantly lower in atrial fibrillation. However, the peak diastolic flow velocities $\left(\mathrm{v}_{\mathrm{y}}\right)$ were not different in both groups of patients.

Atrial fibrillation patients had a significantly longer velocity-time integral of the diastolic forward flow $\left(\mathrm{VTI}_{\mathrm{y}}\right)$ and shorter $\left(\mathrm{VTI}_{\mathrm{x}} /\right.$ $\mathrm{VTI}_{\mathrm{y}}$ ) in comparison to patients in normal sinus rhythm $(\mathrm{p}<0.004, \mathrm{p}<0.003$, respectively; table 3). 
Table 2. Transesophageal measurement of pulmonary venous flow timing in 38 patients with mitral stenosis (in seconds)

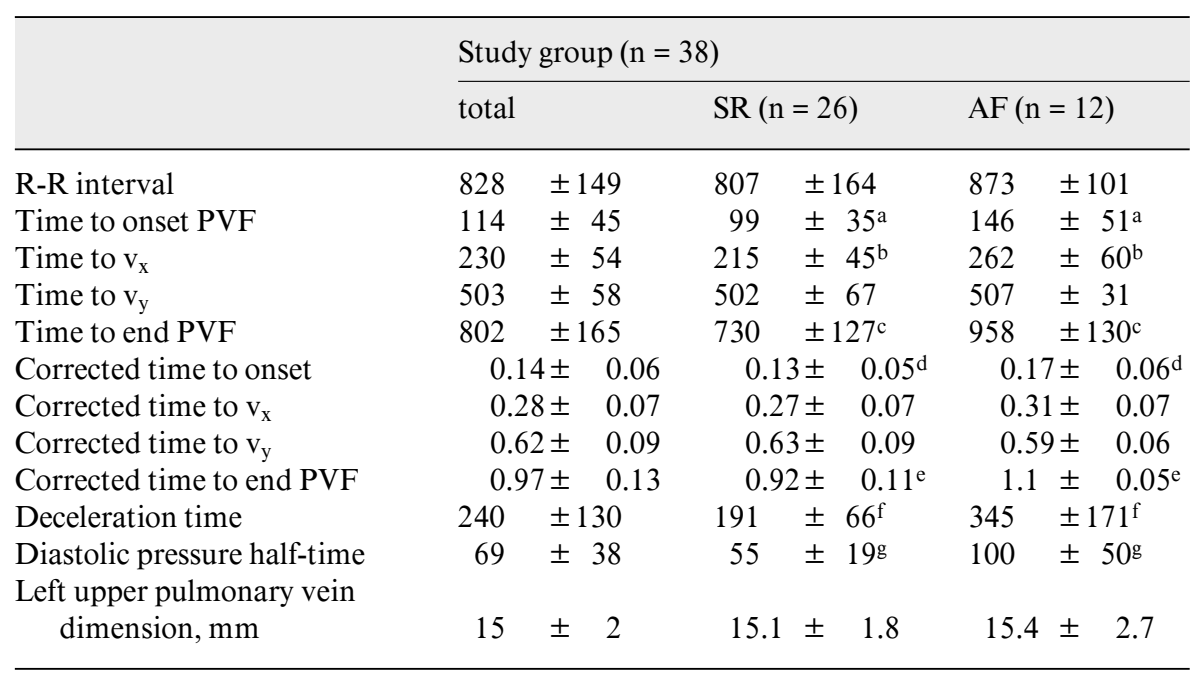

$\mathrm{SR}=$ Sinus rhythm; $\mathrm{AF}=$ atrial fibrillation .

${ }^{\mathrm{a}} \mathrm{p}<0.002,{ }^{\mathrm{b}} \mathrm{p}<0.01,{ }^{\mathrm{c}} \mathrm{p}<0.02,{ }^{\mathrm{d}} \mathrm{p}<0.022,{ }^{\mathrm{e}} \mathrm{p}<0.04,{ }^{\mathrm{f}} \mathrm{p}<0.01,{ }^{\mathrm{g}} \mathrm{p}<0.02$.

Table 3. TEE measurement of pulmonary venous peak flow velocities and velocity-time integrals in 38 patients with mitral stenosis

\begin{tabular}{|c|c|c|c|}
\hline \multirow[b]{3}{*}{ Systolic peak flow velocity $\left(\mathrm{v}_{\mathrm{x}}\right), \mathrm{cm} / \mathrm{s}$} & \multicolumn{3}{|c|}{ Study group $(n=38)$} \\
\hline & total & $\mathrm{SR}(\mathrm{n}=26)$ & $\mathrm{AF}(\mathrm{n}=12)$ \\
\hline & \pm 13 & $\pm 13^{\mathrm{a}}$ & $\pm 9^{\mathrm{a}}$ \\
\hline Diastolic peak flow velocity $\left(\mathrm{v}_{\mathrm{y}}\right), \mathrm{cm} / \mathrm{s}$ & $26 \pm 8.2$ & $26 \pm 9$ & $26 \pm 7$ \\
\hline Systolic/diastolic peak velocity $\left(\mathrm{v}_{\mathrm{x}} / \mathrm{v}_{\mathrm{y}}\right)$ & $1.16 \pm 0.46$ & $1.33 \pm 0.44^{b}$ & $0.85 \pm 0.36^{\mathrm{b}}$ \\
\hline Atrial reversal peak flow velocity $\left(\mathrm{v}_{\mathrm{z}}\right), \mathrm{cm} / \mathrm{s}$ & $18 \pm 9.3$ & $18 \pm 9.3$ & - \\
\hline Systolic velocity-time integral $\left(\mathrm{VTI}_{\mathrm{x}}\right), \mathrm{cm}$ & \pm 3 & \pm 3 & \pm 2 \\
\hline Diastolic velocity-time integral $\left(\mathrm{VTI}_{\mathrm{y}}\right), \mathrm{cm}$ & \pm 4 & $\pm 3^{c}$ & $\pm 5^{\mathrm{c}}$ \\
\hline $\begin{array}{l}\text { Systolic/diastolic velocity-time integral } \\
\left(\mathrm{VTI}_{\mathrm{x}} / \mathrm{VTI}_{\mathrm{y}}\right)\end{array}$ & $0.94 \pm 0.57$ & $1.15 \pm 0.56^{\mathrm{d}}$ & $0.49 \pm 0.24^{\mathrm{d}}$ \\
\hline $\begin{array}{l}\text { Atrial reversal velocity-time integral } \\
\quad\left(\mathrm{VTI}_{\mathrm{z}}\right), \mathrm{cm}\end{array}$ & \pm 1 & \pm 1 & 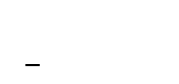 \\
\hline
\end{tabular}

$\mathrm{SR}=$ Sinus rhythm; $\mathrm{AF}=$ atrial fibrillation

${ }^{\mathrm{a}} \mathrm{p}<0.01,{ }^{\mathrm{b}} \mathrm{p}<0.004,{ }^{\mathrm{c}} \mathrm{p}<0.004,{ }^{\mathrm{d}} \mathrm{p}<0.003$. 


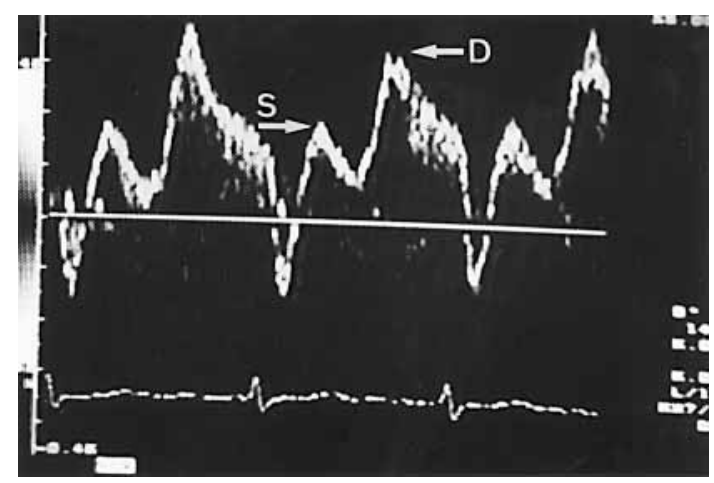

Fig. 2. A transesophageal recording of left upper pulmonary venous flow in a patient with severe mitral stenosis and atrial fibrillation. The systolic (S) to diastolic (D) flow is markedly decreased. Note the markedly prolonged pulmonary venous diastolic flow deceleration.

Time to the start and end of pulmonary venous flow was also significantly delayed in atrial fibrillation patients in comparison with those in sinus rhythm even after correction for heart rate (table 2). Finally, the pulmonary venous diastolic deceleration time and the pressure half-time were significantly prolonged in atrial fibrillation patients as compared to sinus rhythm patients $(\mathrm{p}<0.01, \mathrm{p}<$ 0.02 , respectively).

\section{Univariate Correlates of Pulmonary}

Venous Flow

There was a significant negative correlation between systolic peak flow velocity $\left(\mathrm{v}_{\mathrm{x}}\right)$ and mean pulmonary artery pressure $(\mathrm{r}=$ $-0.424, p=0.011)$, systolic velocity-time integral $\left(\mathrm{VTI}_{\mathrm{x}}\right)$ and mean pulmonary artery pressure $(r=-0.427, p=0.011)$. The pulmonary venous diastolic pressure half-time correlated with peak mitral gradient $(\mathrm{r}=-0.327, \mathrm{p}=$ $0.045)$, mean mitral gradient $(\mathrm{r}=-0.369, \mathrm{p}=$ $0.022)$ and Doppler mitral valve area $(\mathrm{r}=$ $-0.422, \mathrm{p}=0.008)$.

Transesophageal Doppler Echocardiographic Pattern of Pulmonary Venous Flow in Severe Mitral Stenosis

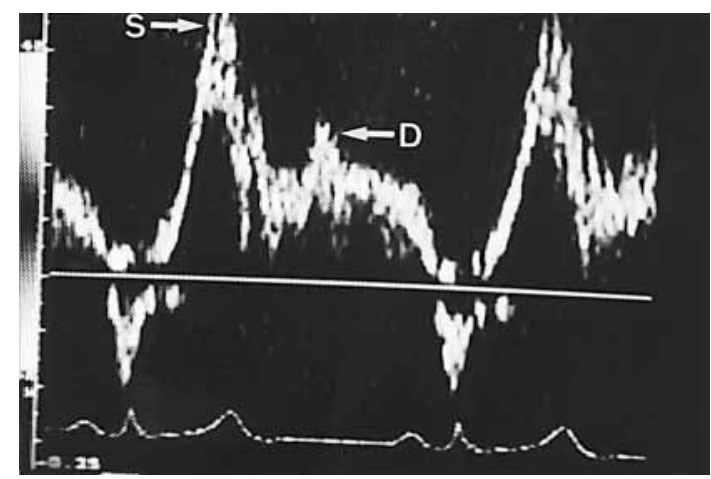

Fig. 3. A transesophageal recording of left upper pulmonary venous flow in a patient with severe mitral stenosis and sinus rhythm. The systolic (S) to diastolic (D) flow ratio is normal.

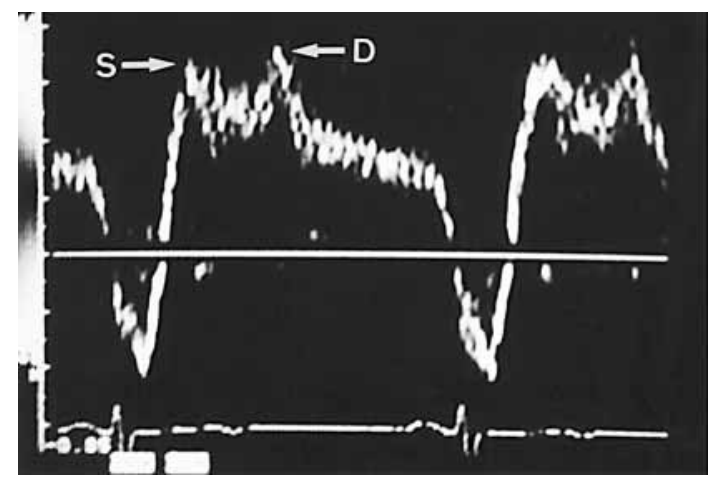

Fig. 4. A transesophageal recording of left upper pulmonary venous flow in a patient with severe mitral stenosis and sinus rhythm. The systolic (S) to diastolic (D) flow is decreased and the diastolic deceleration phase is prolonged.

\section{Discussion}

The pattern of the pulmonary venous flow, characterized both by TEE and transthoracic echocardiography, normally consists of higher systolic and lower diastolic forward waves

Med Principles Pract 1999;8:126-133 131 
and an atrial reversal wave in sinus rhythm [2, $8]$. The systolic forward wave occurs during ventricular systole and is related to atrial relaxations $[1,8]$ and the descent of the base of the heart $[3,9,10]$. On the other hand, the diastolic forward wave occurs during ventricular diastole and is related to the opening of the mitral valve, the rapid inflow of blood into the left ventricle, and decay in the pressure gradient between the left atrium and the left ventricle. The systolic reversal wave results from a retrograde flow following atrial contractions $[1,8]$.

Mitral stenosis markedly alters the pulmonary venous flow as measured by Doppler TEE. It results in a lower pulmonary vein peak systolic flow velocity and prolonged decay in the wave deceleration during diastole. Such changes are more significant in atrial fibrillation $[3,11,12]$.

The TEE pulmonary venous flow patterns in patients with varying severity of mitral stenosis have been previously characterized by Klein et al. [11] and Tabata et al. [3], but only Jolly et al. [12] reported the pulmonary venous flow dynamics in 14 patients with severe mitral stenosis (mean MVA $0.8 \pm 0.1 \mathrm{~cm}^{2}$ ) in sinus rhythm. Our study includes 38 patients all with severe mitral stenosis both in sinus rhythm and atrial fibrillation. It confirms the findings of the previous studies with significantly lower peak systolic flow velocity and systolic velocity-time integral in severe mitral stenosis and atrial fibrillation. The peak systolic flow velocity correlated negatively with the mean pulmonary artery pressure but has no correlation with the left atrial dimension, which may be attributed to the homogeneous type of patients being studied with severe mitral stenosis and large left atrial dimension in all of them. Furthermore, in our study the mean values of peak systolic $\left(\mathrm{v}_{\mathrm{x}}\right)$ and peak diastolic $\left(\mathrm{v}_{\mathrm{y}}\right)$ flow velocities in both groups of patients were significantly lower than those in
Tabata et al. [3] and Klein et al. [11] and this may be explained by the inclusion of mild and severe mitral valve stenosis in their studies, while all our study patients had severe mitral stenosis. On the other hand our mean value of peak systolic flow velocity in sinus rhythm patients is consistent with that reported by Jolly et al. [12].

The pulmonary venous diastolic forward wave in mitral stenosis patients showed a peak in the rapid filling phase and a gradual descending slope in velocity during mid to late diastole reflecting prolonged decay of the left atrial to left ventricular diastolic pressure $[1,8,11,13]$. Fortunately no patient had been excluded from our study because of indistinct pattern with turbulent flow. The present study failed to confirm any correlation between the pulmonary diastolic pressure half-time and the mitral pressure half-time shown by the study of Klein et al. [11]. This may reflect the importance of local atrial factors other than the severity of mitral stenosis in affecting pulmonary venous flow including rhythm abnormalities, left atrial pressure and compliance. The present study of pulmonary venous flow in mitral stenosis showed significant delay in its onset and termination in atrial fibrillation patients, compared to sinus rhythm patients even after correction for heart rate. This may be due to prolonged decay in the left atrial pressure in diastole. This causes the pulmonary vein flow to persist with or even after the start of the next cardiac cycle. Furthermore, the diastolic velocity-time integral $\left(\mathrm{VTI}_{\mathrm{y}}\right)$ in atrial fibrillation was significantly higher than that in sinus rhythm in spite of similar peak diastolic flow velocity reflecting the prolonged deceleration of the pulmonary venous diastolic phase.

The effect of this prolonged diastolic phase deceleration in atrial fibrillation was also seen by the lower ratio of $\mathrm{VTI}_{\mathrm{x}} / \mathrm{VTI}_{\mathrm{y}}$ than the ratio of $\mathrm{v}_{\mathrm{x}} / \mathrm{v}_{\mathrm{y}}$ in the same group. Although our pa- 
tients have the most severe degree of mitral stenosis among the published studies, some of our patients, especially those in sinus rhythm, have nonblunted systolic flow. Whether this is related to the left atrial compliance or other hemodynamic factors requires further investigation.

In conclusion, in patients with severe mitral stenosis there is a significantly lower pul- monary peak systolic flow velocity and prolonged decay in the wave deceleration during diastole. These changes are more marked in atrial fibrillation. These results can help to understand the hemodynamics of severe mitral stenosis and its interaction with the pulmonary circulation. It also adds to the list of pulmonary venous flow changes in various cardiac diseases.

\section{References}

1 Keren G, Sherez J, Megidish R, Levitt $\mathrm{R}$, Laniado $\mathrm{S}$ : Pulmonary venous flow pattern, its relationship to cardiac dynamics: A pulsed Doppler echocardiographic study. Circulation 1985;71:1105-1112.

2 Keren G, Pardes A, Miller HI, Scherez J, Laniado S: Pulmonary venous flow determined by Doppler echocardiography in mitral stenosis. Am J Cardiol 1990;65:246-249.

3 Tabata T, Oki T, Fukuda N, Iuchi A, Kawano T, Manabe K, Tanimoto M, Kageji Y, Sasaki M, Hama M, Ito S: Transesophageal pulsed Doppler echocardiographic study of pulmonary venous flow in mitral stenosis. Cardiology 1996;87:112118.

4 Yoshida K, Yoshikawa J, Yamaura Y, Hozumi T, Akasaka T, Fukaya T: Assessment of mitral regurgitation by biplane transesophageal color Doppler flow mapping. Circulation 1990;82:1121-1126.
5 Klein AL, Obarski TP, Stewart WJ, Casale PN, Pearce GL, Husbands K, Cosgrove DM, Salcedo EE: Transesophageal Doppler echocardiography of pulmonary venous flow: A new marker of mitral regurgitation severity. J Am Coll Cardiol 1991; 18 : 518-526.

6 Teague SM, Heinsimer JA, Anderson JL, Sublett K, Olson EG, Voyles WF, Thadani U: Quantification of aortic regurgitation utilizing continuous wave Doppler. J Am Coll Cardiol 1986;8:592-599.

7 Cohen MV, Gorlin R: Modified orifice equation for the calculation of valve area. Am Heart J 1972;84: 839-840.

8 Klein AL, Tajik AJ: Doppler assessment of pulmonary venous flow in healthy subjects and in patients with heart disease. J Am Soc Echocardiogr 1991;4:379-392.

9 Iuchi A, Oki T, Ogawa S, Kawano T, Hayashi M, Aoyama Y, Emi S, Hosoi K, Fukuda N, Mori H: Evaluation of pulmonary venous flow velocity pattern in hypertrophied and dilated hearts: A study with transesophageal pulsed Doppler echocardiography. J Cardiol 1991;26:7588.
10 Keren G, Sonnenblick EH, Lejemtel TH: Mitral annulus motion: Relation to pulmonary venous and transmitral flows in normal subjects and in patients with dilated cardiomyopathy. Circulation 1988;78:621629.

11 Klein A, Bailey A, Cohen G, Stewart W, Husbands K, Pearce G, Salcedo E: Effects of mitral stenosis on pulmonary venous flow as measured by Doppler transesophageal echocardiography. Am J Cardiol 1993;72:6672.

12 Jolly N, Arora R, Mohan J, Khalelullah M: Pulmonary venous flow dynamics before and after balloon mitral valvuloplasty as determined by transesophageal Doppler echocardiography. Am J Cardiol 1992; 70:780-784.

13 Basnight MA, Gonzalez MS, Kershenovich SC, Appleton CP: Pulmonary venous flow velocity: Relation to hemodynamics, mital flow velocity and left atrial volume and ejection fraction. J Am Soc Echocardiogr 1991;4:547-558. 